\title{
Imigrantes haitianos no Brasil: vulnerabilidade como lócus do cuidado espiritual
}

\author{
Mary Rute Gomes Esperandio* \\ Marcia Corrêa**
}

\section{Resumo}

Os movimentos migratórios têm crescido consideravelmente nas últimas décadas, mesmo em países em desenvolvimento, como é o caso do Brasil, a exemplo dos imigrantes haitianos. O estudo destaca a contribuição da Bioética de Proteção na compreensão da vulnerabilidade desse grupo e também da Psicologia da Religião no que diz respeito aos mecanismos de caráter religioso/espiritual usados no enfrentamento do estresse e sofrimento. A reflexão tem por base uma pesquisa empírica com participação de 35 haitianos, junto aos quais foram levantados dados sobre as estratégias de enfrentamento (coping) religioso por eles utilizada e os principais conflitos espirituais que podem permear a experiência de imigração. Para além de evidenciar a vulnerabilidade dos imigrantes haitianos, o estudo teve como objetivo apontar tal condição como lócus para o exercício de um cuidado espiritual qualificado, voltado ao empoderamento desse grupo.

Palavras-chave: Coping Religioso/Espiritual. Vulnerabilidade. Imigrantes haitianos. Bioética de Proteção. Psicologia da Religião.

\section{Haitian immigrants in Brazil: vulnerability as a loci for spiritual care}

\footnotetext{
Abstract

Migratory movements have grown considerably in the last decades even in developing countries, as is the case of Brazil, with Haitian immigrants, for instance. The study

* Psicóloga (CRP 08/13082). Doutora em Teologia (EST, 2006), Pós-doutora em Psicologia da Religião (Indiana University South Bend/IN - USA). Professora no Programa de Pós-Graduação em Teologia e no Programa de Pós-Graduação em Bioética da Pontifícia Universidade Católica do Paraná (PUCPR) Curitiba, Brasil. E-mail: mary.esperandio@ pucpr.br. http://lattes.cnpq.br/6314025964600648.

** Teóloga, Licenciada em Ciências Religiosas, Especialista em Bioética (PUCPR). Mestranda em Bioética pela Pontifícia Universidade Católica do Paraná (PUCPR) Curitiba, Brasil. E-mail: marciacorrea.2909@gmail.com http://lattes.cnpq.br/4308134883053338.
} 
highlights both the contribution of Bioethics of Protection and the Psychology of Religion in the understanding of the vulnerability of this group and the spiritual/ religious nature of the mechanisms they use to cope with stress and suffering. The reflection is based on an empirical research undertaken among 35 Haitians migrants to collect data regarding religious coping strategies used by them and the main spiritual conflicts that may permeate their experience of migration. Further than highlighting the Haitian migrants' vulnerability, the study aimed to point out such a condition as a locus for offering a qualified spiritual care, aimed at the empowerment of this group. Key-words: Spiritual/Religious Coping. Vulnerability. Haitian Immigrants. Bioethics of Protection. Psychology of Religion.

\section{Inmigrantes haitianos en Brasil: la vulnerabilidad como locus de lo cuidado espiritual}

\section{Resumen}

Los movimientos migratorios han crecido considerablemente en los últimos decenios, incluso en los países en desarrollo, como es el caso de Brasil, al igual que los inmigrantes haitianos. El estudio pone de relieve la contribución de Protección de Bioética en la comprensión de la vulnerabilidad de este grupo y también la psicología de la religión con respecto al carácter religioso/espiritual de los mecanismos utilizados para hacer frente al estrés y sufrimiento. La reflexión se basa en una investigación empírica con la participación de 35 haitianos, de los que se recogieron los datos sobre las estrategias de manejo (afrontamiento) religiosos utilizados por ellos y los principales conflictos espirituales que pueden penetrar en la experiencia de la inmigración. Además de destacar la vulnerabilidad de los inmigrantes haitianos, el objetivo del estudio fue señalar esta condición como un locus para el ejercicio de un cuidado espiritual cualificado, cuyo objetivo es la potenciación de este grupo.

Palabras clave: Adaptación religiosa/espiritual. La vulnerabilidad de los inmigrantes haitianos. De protección de la Bioética. La psicología de la religión.

\section{Introdução}

O Brasil é um país que nasce da mistura de imigrantes: africanos, portugueses, outros europeus, além dos nativos que aqui viviam. Pero Vaz de Caminha, em 1500, e Américo Vespúcio, em 1501, escreveram ao papa, encantados com a beleza encontrada quando da chegada dos portugueses nestas terras: Tanta beleza, tanta flor, tanto amor, um povo inocente, belo e que anda nu... E interrogam-se: "A terra recém encontrada não seria o paraíso, o Éden perdido na terra"? Achavam que sim! O papa considerou o argumento verossímil e mandou teólogos para estudarem o tal "paraíso perdido"... Cortesão (2013) observa que emergiram questões teológicas perturbadoras: "Se aqui existia o paraíso, por quem tinha Cristo morrido?”; "Eram só os europeus pecadores?”; "A inocência existia na 
terra?” (CORTESÃO, 2013). A Teologia (representada por seus teólogos) foi convocada a estudar o "paraíso perdido". No desenvolvimento do estudo empreendido foram se configurando resultados como: entrada de imigrantes diversos, dizimação de povos indígenas, exploração das riquezas naturais, instauração da iniquidade no que imaginavam ser o paraíso perdido. Questões teológicas determinaram decisões éticas em relação ao modo de tratar os povos nativos no território brasileiro.

Esse pano de fundo relativo à origem da formação do Brasil faz-nos interrogar também acerca do atual contexto quanto à contribuição da Teologia a respeito dos movimentos migratórios no Brasil, em especial a imigração haitiana. Teria a Teologia algo a dizer sobre esse tema? E a Bioética - como ciência voltada às questões éticas dos processos vitais -, teria também algo a contribuir? Que reflexão teológica e bioética é possível ser empreendida a partir da situação de vulnerabilidade em que se encontram os haitianos imigrantes no Brasil?

Este estudo tem como objetivo contribuir com o debate sobre o tema. Inicialmente, são apresentadas breves notas acerca dos movimentos migratórios no Brasil e, de modo mais particular, se destaca a condição de vulnerabilidade que marca o contexto do movimento migratório haitiano, tornando-o "vulnerados" (diretamente afetados pela vulnerabilidade que se encontram). Qual o papel da religiosidade nesse contexto de vulnerabilidade? $\mathrm{Na}$ sequência, são exibidas as contribuições da Bioética no que diz respeito à noção de vulnerabilidade, "vulnerados", e da Psicologia da Religião sobre a teoria do coping religioso espiritual e dos conflitos espirituais, com vistas a uma melhor compreensão do papel da religião e da espiritualidade entre os imigrantes haitianos. Em seguida, são mostrados os resultados de uma pesquisa empírica realizada junto aos imigrantes haitianos sobre coping (enfrentamento) religioso/espiritual com o objetivo de levantar dados acerca do papel da espiritualidade nesse contexto de vulnerabilidade. O texto conclui destacando tanto a necessidade de políticas públicas que considerem a condição de "vulnerados" dos haitianos, quanto a necessidade de um cuidado espiritual qualificado, que leve em conta os recursos e as necessidades espirituais presentes no processo de enfrentamento da vulnerabilidade a que esse grupo se encontra imerso. 


\section{Breves notas sobre os movimentos migratórios no Brasil e o contexto da imigração haitiana no país}

O intuito desta seção é destacar alguns dados que configuram os movimentos migratórios no Brasil, a fim de apontar o contexto de vulnerabilidade que caracteriza a imigração dos haitianos em solo brasileiro.

O Brasil é um país multicultural desde os seus primórdios. Até 1930, houve significativa entrada de portugueses, espanhóis, italianos, alemães, eslavos (russos, poloneses, ucranianos) e asiáticos (japoneses e sírio-libaneses), com registros de entradas em diferentes épocas, e os dados censitários de recepção de estrangeiros no Brasil "apresentam dificuldade de estimativa”, segundo Patarra (2005, p. 27). De acordo com os dados do Instituto Brasileiro de Geografia e Estatística (IBGE, 2010), até 2000, o número de pessoas nascidas no exterior que vivia no Brasil era de 510.068. Em 2010, esse número caiu para 431.319. Quanto ao movimento migratório haitiano, Uebel (2016, p. 25) observa que este "ganhou destaque nas estatísticas e na imprensa brasileira muito recentemente (2010-2014)". O autor interpreta a situação da migração haitiana em função da "crise econômica internacional aliada à guerra civil e crise humanitária no Haiti bem como a instabilidade econômica e política do país" (UEBEL, 2016, p. 25).

De fato, desde o grande terremoto ocorrido no Haiti, no ano de 2010, e a decorrente escassez de trabalho e de condições de vida naquele país (CUTTI, 2015; FARIA, 2012, p. 15; GOTTARDI, 2015, p. 11; MILESI, 2014; LOUIDOR, 2013; XAVIER, 2012, p. 105), constata-se um constante fluxo de emigração dos haitianos para outros países. Em busca de trabalho e de condições melhores de subsistência, os haitianos se dirigem a países vizinhos e o Brasil é um dos principais destinos. Estados de diversas regiões brasileiras, como Rondônia, Amazonas, São Paulo, Paraná e Rio Grande do Sul, são procurados pelos haitianos (UEBEL, 2015, p. 24). Sobre os motivos pelos quais esse povo tem escolhido o Brasil como um lugar possível para reconstruírem suas vidas, Chiarelo (2011) sugere pelo menos dois fatores: a liderança brasileira na Missão das Nações Unidas para a Estabilização do Haiti (MINUSTAH), e a presença dos militares brasileiros naquele país, declarando apoio humanitário ao Haiti. Entretanto, segundo Milesi (2014), o interesse de parte dos haitianos na vinda para o Brasil foi, na verdade, uma estratégia para alcançar a Guiana Francesa. Porém, com o fechamento das fronteiras daquele país em 2013, estes passaram também a permanecer no território 
brasileiro. Em 2014, já se estimava a existência de mais de 21 mil haitianos com visto humanitário no Brasil.

Entre 2014 e 2016 as mídias anunciavam com frequência, a chegada de imigrantes haitianos, sobretudo nos Estados do Amazonas e do Acre, estabelecendo-se primordialmente em cidades pequenas como Tabatinga (AM), Brasileia (AC), Epitaciolândia (AC), Assis Brasil (AC), Benjamin Constant (AC) e outras (XAVIER, 2012, p. 101). Como o fluxo migratório aumentou vertiginosamente, pelo menos até 2016, ainda não é possível precisar o número de haitianos nesses e em outros municípios amazônicos.

Por se tratar de um fenômeno recente, as fontes de informação sobre a migração dos haitianos são ainda escassas, incompletas e por vezes contraditórias. Como bases de informações o CNIg (Conselho Nacional de Imigração), o CONARE, e a Pastoral do Migrante, a última em grau menor, obtêm seus dados quando os haitianos buscam auxílio nessas entidades. Os registros iniciais dessas instituições entre 2010 e 2011 revelam uma faixa etária de imigrantes haitianos relativamente jovens. Até o mês de julho de 2014 os números da migração haitiana no Brasil eram de aproximadamente 45 mil imigrantes. Destes, aproximadamente nove mil obtiveram autorização de residência junto ao Conselho Nacional de Imigração (CNIg) e 13.564 conseguiram vistos emitidos pelos consulados brasileiros. Em termos de fluxo mensal, para efeito de comparação, o Consulado de Porto Príncipe concede em média 680 vistos, enquanto aproximadamente 40 imigrantes solicitam refúgio ao dia (FERNANDES et al., 2011).

Com o aumento da necessidade de desenvolvimento de políticas migratórias no país e a imprescindível atenção que necessitam as comunidades de migrantes, refugiados e apátridas, alguns Estados brasileiros têm criado planos, convenções e comitês para garantir direitos a essa população. No Paraná, foi constituído em 2012, o Comitê Estadual para Refugiados e Migrantes, pelo Decreto Estadual n ${ }^{\circ}$. 4.280, tendo como objetivo orientar os agentes públicos e manter políticas públicas aptas a assistir, orientar e proteger os direitos de imigrantes (Plano Estadual de Políticas Públicas para a Promoção e Defesa dos Direitos de Refugiados, Migrantes e Apátridas do Paraná, 2014).

O trabalho de UELB (2016) mostra as recentes mudanças da política externa brasileira para imigrantes e refugiados, precisamente no caso dos imigrantes haitianos. Em seu estudo, UELB (2016) observa que ocorreu uma recategorização dos imigrantes haitianos, que saíram do status de "refugiados" 
(próprio da política brasileira de imigração entre 2010 a 2013) para receberem um "visto humanitário". UELB afirma que, em 2015, foram concedidos 43.781 vistos humanitários a imigrantes haitianos que não se enquadravam na condição de "refugiados" (UELB, 2015, p. 35).

Apesar desses mecanismos recentes, ainda há imigrantes em situação de "indocumentados" (CNBB, 2009) e se encontram, assim, em uma situação de vulnerabilidade existencial desde sua origem, em função das condições socioeconômicas, políticas, sociais e ambientais do Haiti, que os empurram à diáspora, engrossando os movimentos migratórios no mundo. Na qualidade de emigrantes, tal vulnerabilidade se exacerba pois vão compor os movimentos ilegais de imigração, tornando-se, muitas vezes, vítimas de violência e exposição a situações degradantes. A vulnerabilidade se acentua na própria chegada ao Brasil e cresce na proporção em que:

- Há uma ausência de laços no país em que se encontram: não tem suporte de redes familiares e sociais - ficam "sem lugar de acolhimento" enquanto não estão empregados (sem trabalho não têm onde viver, o que os tornam mais vulneráveis do que os brasileiros que contam com rede de apoio familiar) (SILVA, S., 2017);

- Carecem de uma percepção das “armadilhas culturais” com as quais ainda não estão familiarizados. Por ainda não terem o domínio da língua portuguesa, a comunicação é dificultada, colocando-os em situação de exploração e de dificuldade de conhecer e reivindicar direitos humanos básicos (MAGALHÃES; BAENINGER, 2016);

- Enquanto "não-cidadãos", necessitam do emprego e não são objeto das políticas assistenciais governamentais que não englobam estrangeiros; submetem-se a condições de trabalho desumanas, trabalhos sujos, pesados, perigosos e mal remunerados (RISSON; MAGRO; LAJÚS, 2017);

- Potencialmente tornam-se simultaneamente objeto de atração e repulsa. A atração se dá quando são vistos como "úteis", enquanto objeto de exploração em sua força de trabalho. São objeto de rechaço quando vistos como "bodes expiatórios" de problemas sociais (DIEHL, 2016) ou como "ameaça" - quer seja para o país e para os serviços ou sistemas de saúde (RODRIGUES; DIAS, 2012; RISSON; MATSUE; LIMA, 2018);

- Estes imigrantes, inicialmente considerados "refugiados ambientais", são pessoas traumatizadas pela violência que sofreram, com alto índice de sofrimento psíquico, com necessidades de toda sorte, incluindo a de atendimento psicológico (FRIEDRICH et al., 2017). 


\section{A contribuição da bioética para o entendimento da situação de vulneração dos imigrantes haitianos}

A Declaração Universal sobre Bioética e Direitos Humanos (DUBDH) aponta o "princípio da vulnerabilidade" como algo que "precisa ser levado em consideração nas aplicações e avanços do conhecimento científico, práticas médicas e tecnologias associadas. Indivíduos e grupos com vulnerabilidade específica precisam ser protegidos e a integridade individual de cada pessoa precisa ser respeitada" (DUBDH, Artigo 8).

Os bioeticistas, Cunha \& Garrafa, destacam que o princípio da vulnerabilidade como exposto pela DUBDH inclui "uma dimensão descritiva, enfatizando a necessidade de 'levar em consideração' a vulnerabilidade humana na aplicação do conhecimento, e uma dimensão prescritiva: o dever de proteger indivíduos e grupos com vulnerabilidade específica" (2016, p. 204).

As pessoas e os grupos que se encontram em condições de vulnerabilidade precisam ser protegidos e ter respeitadas sua integridade e dignidade próprias. Esse entendimento leva-nos à noção de "bioética da proteção", porém, não se trata de uma perspectiva de proteção do tipo paternalista. A bioética de proteção "foi pensada para proteger aqueles que, devido às suas condições de vida, são fragilizados ou vulneráveis a ponto de não poder realizar suas potencialidades e projetos legítimos moralmente" (SCHRAMM, 2009, p. 147). Decorre daí, que uma de suas tarefas é a de "refletir sobre a problemática da sobrevivência do mundo vital e da qualidade de vida de seus integrantes presentes e futuros" (SCHRAMM, 2008 , p. 15). Essa perspectiva amplia a compreensão de vulnerabilidade a que os imigrantes haitianos no Brasil estão expostos, destacando o aspecto da responsabilidade social e coletiva na promoção de melhores condições de vida para essa população não apenas vulnerável, mas também "vulnerada". Essa categoria se refere àqueles que, para além da condição (ontológica ou situacional) de vulneráveis, tornam-se diretamente afetados, a ponto de não lhes ser possível o exercício de suas potencialidades para a construção de uma vida digna e de qualidade (SCHRAMM, 2008, p. 13). Nesse sentido, o exercício de uma bioética de proteção se coloca como desafio, haja vista que os imigrantes necessitam de proteção, auxílio, acompanhamento, políticas públicas, aconselhamento pastoral e espiritual. De que modo a Teologia e a Bioética poderiam contribuir para a redução dos efeitos sociais e individuais de sujeitos em situação de vulneração? 
Estudos apontam que em contexto de vulnerabilidade, sobretudo quando a vida é ameaçada em seus aspectos físicos e emocionais, as pessoas lançam mão de recursos religiosos/espirituais como forma de enfrentamento. Tal comportamento vem sendo descrito na literatura como coping religioso espiritual, como apresentado na seção seguinte.

\section{Coping Religioso/Espiritual (CRE) e conflitos espirituais: contribuição da psicologia da religião na compreensão dos mecanismos de coping (enfrentamento) e dos conflitos espirituais}

A palavra coping não tem uma tradução equivalente em língua portuguesa. Por essa razão, os estudos acadêmicos têm mantido a palavra em seu formato original, que quer dizer "enfrentamento", "modo de lidar com". Coping é uma atividade humana universal, que se apresenta como oportunidade e como desafio (CUMMINGS \& PARGAMENT, 2010, p. 29). Os teóricos do coping nomeiam como "estressores" os eventos ou situações que afetam o bem-estar de um indivíduo e demandam esforço de adaptação a fim de restaurar o bem-estar.

A experiência de migração, por exemplo, caracteriza uma situação potencial de sofrimento que requer esforço nas estratégias de coping. Contudo, segundo Folkman (1984), um evento estressor não é causa de estresse por si só. Na teoria do estresse e do coping, construída por Folkman \& Lazaus (1980), os autores apontam que o sofrimento produzido por um evento estressor está diretamente relacionado à percepção e resposta do indivíduo a tal evento. Desse modo, percepção e resposta do indivíduo são conceitos chaves na teoria do coping. Os autores defendem que é próprio do ser humano avaliar as circunstâncias com a finalidade de definir formas de se responder a elas. Uma primeira etapa do processo, chamada de "avaliação primária", visa classificar o evento estressor em uma das três categorias: desafio, ameaça e perda. Desafios representam oportunidades para alcançar resultados desejados. Nesse caso, os eventos estressores são considerados positivos. Já as circunstâncias que reduzem a capacidade do indivíduo em manter um objeto valorizado serão avaliadas como ameaças e tendem a criar ansiedade no sujeito. Quanto às avaliações de perdas, estas se referem à percepção que a pessoa tem de ter sido privada de algo que valoriza; a reação comum à perda é a alteração do humor (como tristeza, pena, angústia, ansiedade). 
Quando uma situação é avaliada como sendo intensamente estressora, uma segunda avaliação ocorre e o indivíduo verifica seu potencial (e possibilidades) de dar uma resposta bem-sucedida ao evento estressor. As situações percebidas como nocivas e maiores do que a capacidade do indivíduo de lidar com elas causam angústia profunda. Lazarus \& Folkman (1984) observaram que, em geral, os indivíduos respondem aos eventos estressores de dois modos: "com foco no problema" (Problem-focused coping) ou "com foco nas emoções" (emotion-focused coping).

Com base na teoria de teoria de coping, de Folkman \& Lazarus (1980), o psicólogo da religião, Kenneth Pargament (1997), observou que muitas pessoas usavam estratégias de caráter religioso/espiritual para lidar com o estresse e sofrimento. Tais estratégias tanto podiam ser voltadas à solução de problemas quanto voltadas às emoções. Ele constatou, por exemplo, que pessoas se sentiam colaboradoras de Deus na resolução de problemas, ou se sentiam menos ansiosas ao fazerem o que consideravam ser sua parte, “deixando Deus fazer o restante" (PARGAMENT, 1997). Desse modo, o autor chegou ao conceito de coping religioso/espiritual, e o definiu como sendo o uso de estratégias de caráter religioso/espiritual para lidar com eventos estressores (CUMMINGS \& PARGAMENT, 2010, p. 30).

Contudo, nem todas as estratégias espirituais/religiosas são positivas. De acordo com Pargament et al. (1998, p. 712), o coping religioso/espiritual (CRE) pode ser positivo ou negativo. O CRE Positivo se refere ao senso de espiritualidade, a um relacionamento seguro com Deus, à crença de que existe um sentido na vida a ser encontrado, e ao senso de conexão com outros. Compõem um padrão de coping religioso/espiritual positivo métodos de enfrentamento tais como: reavaliação religiosa positiva; coping religioso/ espiritual colaborativo; busca de suporte espiritual, transformação de si e de sua vida, busca de ajuda da instituição religiosa etc.

O coping religioso/espiritual negativo se expressa por meio de um relacionamento menos seguro com Deus, uma visão de mundo frágil e ameaçadora e presença de conflitos espirituais na busca de propósito e sentido. Compõem um padrão de CRE negativo um conjunto de métodos tais como: reavaliação religiosa punitiva, descontentamento espiritual, reavaliação do poder de Deus, entre outros (PARGAMENT, 1998, p. 712).

Pargament et al. elaboraram uma Escala de Coping Religioso/Espiritual com 14 itens, e duas subescalas, cada uma com sete itens, para avaliar o uso positivo de CRE e o uso negativo de CRE. 
A maioria dos estudos sobre coping religioso/espiritual evidencia, em geral, um uso positivo de coping. Mas a utilização de coping religioso/espiritual negativo tem chamado a atenção dos pesquisadores. O CRE Negativo está fortemente associado à presença de conflitos espirituais.

Embora haja um número bastante expressivo de estudos mostrando maior uso de coping religioso positivo, Julie Exline \& Pargament apontaram também a presença de conflitos espirituais em situações de estresse e sofrimento. Conflitos espirituais ocorrem quando alguns aspectos das crenças, práticas, ou experiências religiosas/espirituais tornam-se foco de pensamentos ou emoções negativas, preocupações ou crises (EXLINE et al., 2014).

Exline e Pargament desenvolveram uma Escala de Conflitos Espirituais composta por 26 itens, que avalia três tipos básicos de conflitos: 1. Conflitos sobrenaturais (desdobram-se em Conflitos Divinos e Conflitos Demônicos); 2. Conflitos Interpessoais; 3. Conflitos Intrapessoais (desdobram-se em três tipos de conflitos: Conflitos Morais; Conflitos relacionados à Dúvidas; Conflitos de Sentido Último.

Os Conflitos Divinos se referem à angústia ou emoções negativas relacionados à crença em Deus ou na relação percebida com Deus. Por exemplo, a pessoa pode sentir raiva de Deus em função de orações não respondidas, ou se sentir punida por Deus por alguma razão. Conflitos Demônicos envolvem a preocupação de que forças do mal ou espíritos malignos estejam atacando o indivíduo ou causando eventos negativos. Conflitos Interpessoais estão relacionados à experiências negativas com pessoas religiosas ou instituições, ou mesmo conflitos com outras pessoas em torno de questões religiosas. Os Conflitos Intrapessoais têm um foco interno nos próprios pensamentos ou ações do indivíduo. Os Conflitos Morais expressam os conflitos de um indivíduo em relação a princípios morais que considera corretos, ou o sentimento de culpa excessiva em resposta à percepção de transgressões (por exemplo, uma pessoa pode se sentir culpada por não viver de acordo com os seus padrões morais ou em conflito para seguir os seus princípios morais). Conflitos relacionados a Dúvidas se referem a perguntas sobre as suas crenças (por exemplo, uma pessoa pode se sentir confusa ou perturbada por dúvidas a respeito das crenças religiosas ou espirituais, tais como a existência de Deus ou da vida após a morte). Os Conflitos de Sentido Último se referem ao sentimento de angústia que surge da falta de sentido e propósito na vida (por exemplo, o indivíduo questiona se a vida realmente importa). 
Tanto a Escala de Coping Religioso/Espiritual quanto a Escala de Conflitos Espirituais possuem cinco níveis de respostas para cada item, indo desde o "Nem um pouco/Não se aplica" até o "Muitíssimo".

Visando pois, compreender de que modo os haitianos fazem uso do coping religioso/espiritual para lidar com o sofrimento vivenciado no processo de imigração e avaliar também a presença de conflitos espirituais, foi empreendido um estudo com a aplicação da Escala Breve de Coping Religioso/Espiritual e da Escala de Conflitos Espirituais junto a um grupo de 52 imigrantes haitianos.

\section{A pesquisa sobre o papel da religiosidade/espiritualidade entre os imigrantes haitianos}

A presente pesquisa faz parte de um estudo mais amplo que tem como um de seus objetivos a validação das escalas aqui utilizadas e sua aplicabilidade na pesquisa sobre espiritualidade/religiosidade nos mais variados contextos de estresse e sofrimento. A coleta dos dados para a validação das escalas vêm sendo realizada tanto junto à população geral, quanto em grupos específicos, como por exemplo, entre pacientes com câncer, idosos hospitalizados, pacientes psiquiátricos e também junto a imigrantes haitianos, como é o caso do presente estudo. Assim, o estudo mais amplo recebeu parecer de aprovação do Comitê de Ética em Pesquisa da PUCPR, sob número 1.354.361, de $07 / 12 / 2015$. As amostras entre imigrantes haitianos foram coletadas entre janeiro e agosto de 2016.

\subsection{Método}

Trata-se de um estudo de caráter quantitativo, descritivo e de corte transversal (a amostra é coletada em uma única vez).

A amostra, caracterizada por conveniência, contou com a participação de imigrantes haitianos frequentadores de duas igrejas em Curitiba, sendo uma de tradição Católica e a outra de tradição Protestante, Menonita. Cinquenta e dois imigrantes haitianos foram convidados para participar da pesquisa. Contudo, foram validados os dados de 35 participantes. Dezessete amostras foram invalidadas por não terem sido finalizadas. Foi aplicado um questionário para o levantamento dos dados sociodemográficos e as duas Escalas mencionadas: Escala CRE-Breve 14 e Escala de Conflitos Espirituais. Entre os critérios de inclusão foram considerados: a capacidade 
de compreensão das questões, ser maior de 18 anos e assinar o Termo de Consentimento Livre e Esclarecido. Dois pesquisadores treinados participaram na coleta dos dados.

Após a coleta, os dados foram transferidos para o SPSS 21.0 (Statistical Package for Social Sciences, versão 21.0) para a análise estatística.

\subsection{Resultados}

\subsubsection{Caracterização da população pesquisada}

Entre os participantes, 24 pessoas eram do sexo masculino e 11 do sexo feminino, com média de idade de 32,4 (mínima de 20 e máxima de 48). Foram aplicados os seguintes instrumentos: 1) Questionário para o levantamento de dados sociobiodemográficos; 2) Escala de Coping Religioso Espiritual Breve 14 itens (CRE-Brief); 3) Escala de Conflitos Espirituais.

Quanto ao estado civil, 34,3\% eram casados, 60\% solteiros e 5,7\% divorciados. Em relação à qualificação profissional no país de origem, pôdese constatar uma grande variedade, desde cabeleireira, carpinteiro, pintor, motorista, enfermeira, e outras profissões, e um maior número de professores, $17,1 \%$, e 11,4\% de trabalhadores da construção civil. No Brasil, também predominou o trabalho na área da construção civil, com 17,1\%, e apenas $2,9 \%$ reportaram trabalhar como professor. O restante, cerca de $60 \%$, compõe uma extensa gama de profissões como: garçom, serviços gerais, cozinheiro, mecânico etc. A remuneração salarial é baixa, sendo 54,3\% com ganhos na faixa de dois salários mínimos e apenas 5,7\% na faixa entre 2 e menos de cinco salários mínimos. Da amostra, 40\% não informaram o nível econômico. Contudo, 62,9\% dos participantes encontravam-se desempregados.

Quanto ao nível de escolaridade, $17,1 \%$ da amostra completaram o Ensino Fundamental contra 20\% que não o fizeram. 22,9\% têm Ensino médio e igual porcentagem de não concluintes. 5,7\% completaram o curso superior, igual porcentagem de não concluintes, e mesma porcentagem, de 5,7\%, com Pós-Graduação.

Os dados apontam que a minoria dos imigrantes haitianos possui alto nível de escolaridade $(11,4 \%)$ e a maioria, cerca de $82 \%$, tem até o ensino médio.

À época da coleta de dados, no primeiro semestre de 2016, 60\% dos participantes residiam no Brasil pelo período entre 1 e 3 anos; $11 \%$ com menos de um ano, e 8,6\% com tempo entre 3 anos e um mês e 5 anos. 57\% dos 
haitianos afirmam ter entrado sozinhos no Brasil, enquanto $43 \%$ da amostra declaram ter entrado no Brasil acompanhados de algum membro da família.

\subsubsection{Coping (enfrentamento) Religioso Espiritual utilizado pelos Imigrantes Haitianos}

A Escala de Coping Religioso Espiritual Breve, de 14 itens, é composta por duas subescalas: Coping Religioso/Espiritual Positivo e Coping Religioso/ Espiritual Negativo (ESPERANDIO et al., 2018).

Compõem o Coping Religioso/Espiritual Positivo as seguintes afirmações:

P1. Procurei uma ligação maior com Deus

P2. Procurei o amor e a proteção de Deus

P3. Busquei ajuda de Deus para me livrar da minha raiva

P4. Tentei colocar meus planos em ação com a ajuda de Deus

P5. Tentei ver como Deus poderia me fortalecer nessa situação

P6. Pedi perdão pelos meus erros (ou pecados)

P7. Foquei a religião para parar de me preocupar com meus problemas

Compõem o Coping Religioso Espiritual Negativo as seguintes afirmações:

N1. Fiquei imaginando se Deus tinha me abandonado

N2. Senti-me punido por Deus pela minha falta de fé

N3. Fiquei imaginando o que eu fiz para Deus me castigar

N4. Questionei o amor de Deus por mim

N5. Fiquei imaginando se meu grupo religioso tinha me abandonado

N6. Cheguei à conclusão que forças do mal atuaram para isso acontecer

N7. Questionei o poder de Deus

Os parâmetros de pontuação dos valores da escala são os seguintes: Nenhuma ou Irrisória: 1.00 a 1.50; Baixa: 1.51 a 2.50; Média: 2.51 a 3.50; Alta: 3.51 a 4.50; Altíssima: 4.51 a 5.00.

Os resultados indicam que a prevalência no uso de estratégias de coping religioso/espiritual para lidar com o estresse e sofrimento é significativa, sendo que $46,2 \%$ dos imigrantes haitianos fazem alto uso de CRE Positivo, segundo os parâmetros de pontuação dos valores da escala; 7,7\% fazem um uso médio de estratégias de CRE Positivo, 30,8\% fazem um uso baixo de CRE Negativo e 15,4\% fazem um uso médio de CRE Negativo. O Coping Religioso 
Positivo é bem mais empregado (3.7) do que o Negativo (2.2).

As principais estratégias de CRE com mais alta pontuação mostram o uso da religião para a transformação da vida; indicam uma reavaliação religiosa/espiritual positiva; apontam o uso da religião como fonte de conforto para o sofrimento, e revelam, ainda, comportamentos colaborativos com o divino, na busca de solução para os problemas.

Isso pode ser evidenciado nas médias consideradas altas nos fatores "Reavaliação Religiosa Positiva", onde itens que compõem esse fator obtiveram uma pontuação alta segundo os parâmetros da Escala, por exemplo: "Procurei uma ligação maior com Deus": 3.69; "Procurei o amor e a proteção de Deus": 4.11. Além disso, tal comportamento positivo expressa um estilo colaborativo na solução de problemas, com uma pontuação considerada alta: "Tentei colocar meus planos em ação com a ajuda de Deus": 4.34 (Gráfico 1).

O fator que expressa a utilização de CRE com vistas à "Transformação de si e de sua vida", pode ser constatado com as seguintes pontuações: "Tentei ver como Deus poderia me fortalecer nesta situação": média alta de 3.83; "Pedi perdão pelos meus erros/pecados: média alta de 3.77"; "Busquei ajuda de Deus para me livrar da minha raiva: média alta de 3.63. O CRE Positivo mais baixo obteve uma pontuação considerada média de acordo com os parâmetros de pontuação da escala: "Foquei na religião para parar de me preocupar com os meus problemas": 3.17 (Gráfico 1).

Quanto às estratégias CRE Negativo (Gráfico 1), estas variam entre uma pontuação média e baixa, sendo que houve maior pontuação em relação à reavaliação negativa de Deus: "Questionei o amor de Deus por mim": 3.11 e "Questionei o poder de Deus": 2.83. As outras estratégias de CRE Negativo tiveram uma pontuação média considerada baixa, de acordo com os parâmetros de pontuação dos valores da escala, conforme demonstrado nos primeiros sete itens do Gráfico 1. 


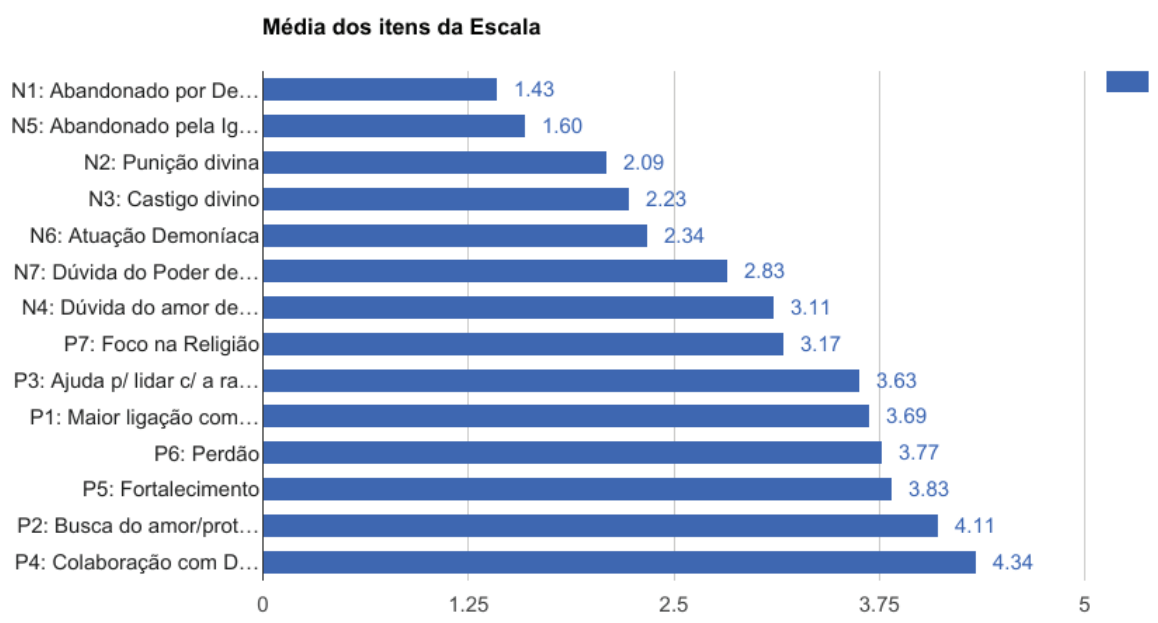

Gráfico 1. Média de Pontuação dos itens da Escala CRE-Breve Fonte: As autoras.

\subsubsection{Conflitos Espirituais na experiência de imigração}

Quanto à aplicação da Escala de Conflitos Espirituais (Gráfico 2), os resultados revelam certa presença de conflitos. Dos 26 itens que compõem a escala, 16 deles (do tipo Divino, Demônico, Interpessoal e Dúvidas) tiveram parâmetros de pontuação baixa. Entretanto, os outros 10 itens da Escala, que dizem respeito aos conflitos do tipo Sentido Último e Moral, apresentaram parâmetros de pontuação média. Destaca-se, contudo, que dois itens que compõem os conflitos Morais e os de Sentido Último, obtiveram pontuação alta de acordo com os parâmetros dos valores da Escala: "Questionei-me se a vida realmente tem importância" (3.63), e "Lutei tentando seguir os meus princípios morais" (3.57).

A pontuação considerada alta nesses dois itens chama a atenção por sugerir a presença de sintomas depressivos, ${ }^{1}$ uma vez que há dúvida sobre se a vida vale a pena, e aliado a isso, há dificuldades em seguir os próprios princípios morais.

Dois aspectos são importantes a serem considerados aqui. O primeiro é que em razão da população pesquisada fazer um alto uso de coping religioso

1 A dúvida sobre a importância da vida não apenas indica possível sintoma de depressão, como pode também apontar questões mais graves, como por exemplo a presença de “ideação suicida". Isso, porém não foi investigado em nossa pesquisa. 
positivo, tal comportamento pode ser preditivo de melhor solução dos conflitos espirituais relacionados ao sentido da vida.

Ligado a este, o outro aspecto é que não se pode esperar que a solução dos conflitos espirituais resolva simplesmente em função dos recursos espirituais apresentados. A reavaliação religiosa positiva é um recurso importante, preditivo de melhores resultados em saúde. Mas precisa ser estimulada. Nesse sentido, a própria condição de vulnerabilidade tornase o lócus do cuidado espiritual. Na prestação de cuidado espiritual a esse grupo, o/a cuidador pastoral/espiritual pode reforçar tais recursos espirituais internos, colocando-os a serviço de maior empoderamento desse grupo, principalmente ao ajudá-los no manejo dos conflitos espirituais morais e de sentido último.

\section{Subescalas de Conflitos Espirituais}

3.50

3.00

\subsection{7}

2.92

2.50
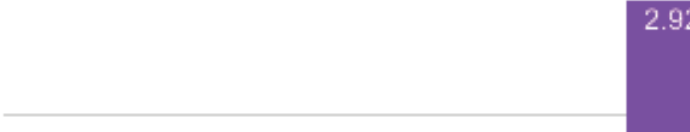

2.00

1.50

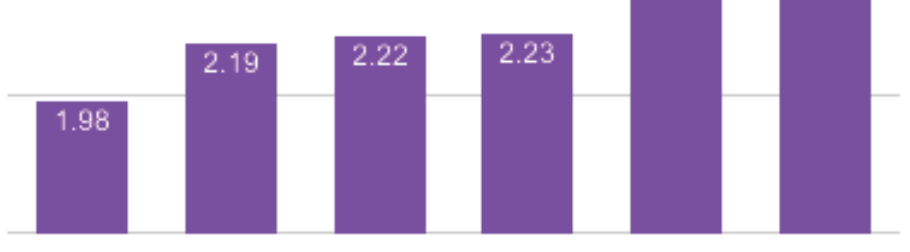

Interpessoal

Dúvidas

Divino

Demônico

Sentido Último

Gráfico 2. Subescalas de Conflitos Espirituais

Fonte: As autoras.

\subsection{Discussão}

Os dados revelam que a religiosidade/espiritualidade é, de modo geral, positiva e altamente utilizada pelos imigrantes haitianos, indicando o coping religioso espiritual positivo como um recurso relevante no enfrentamento das 
condições existenciais desfavoráveis, dos desafios, das ameaças e das próprias perdas que os motivam à diáspora. Percebe-se também, a presença de alguns conflitos espirituais importantes, sugerindo a necessidade de um cuidado e acompanhamento espiritual a esse grupo.

Considerando a situação de vulnerabilidade em que se encontram, chama a atenção a dúvida sobre se a vida realmente importa. Nota-se, dessa forma, que o processo de imigração parece ter implicações nos questionamentos existenciais dos indivíduos estudados. Contudo, o alto uso de estratégias de coping positivo são favoráveis à solução dos conflitos espirituais apresentados, funcionando como uma espécie de antídoto para a depressão. Segundo os estudos de Desai e Pargament (2015), quando o sujeito encontra sentido e propósito na experiência de conflito espiritual, tal experiência pode ser representativa de transformação e crescimento pessoal e não necessariamente um preditor de piores desfechos em saúde mental e bem-estar.

Destaca-se que o "n" de 35 representa os dados válidos para a análise de um total de 52 aplicações dos instrumentos da pesquisa. Nesse sentido, por ser um número pequeno de participantes, há limites nas generalizações dos resultados. Uma das principais dificuldades encontradas na coleta de dados foi a questão da língua, pois muitos deles ainda enfrentam problemas no domínio da língua portuguesa. Outra dificuldade relaciona-se ao atual contexto socioeconômico brasileiro. Houve, recentemente, aumento na taxa de desemprego no país. A pesquisa aponta a alta prevalência de haitianos desempregados $(62,9 \%)$, o que os leva à continuidade no movimento migratório para países vizinhos. No processo de coleta, várias amostras não puderam ser concluídas em razão de que um número significativo desse grupo havia se mudado para o Chile.

Considerando a assistência prestada pelas instituições religiosas brasileiras aos haitianos imigrantes, há que se considerar a situação de vulnerabilidade como um fator importante no cuidado espiritual desse grupo. O coping religioso/espiritual positivo apresenta-se como um recurso importante no enfrentamento do sofrimento experienciado no processo de imigração. Desse modo, as estratégias positivas podem ser estimuladas e reforçadas como meio de lidar com os conflitos espirituais que aí se fazem presentes, oportunizando maior crescimento e transformação, a despeito da situação de vulnerabilidade, tornando-se, a própria vulnerabilidade, o material por meio do qual se poderão engendrar processos de transformação pessoal e/ou mesmo grupal. 
A Bioética auxilia na reflexão, na busca da sabedoria como disciplina para a ação. Sabedoria "definida como o conhecimento de como usar o conhecimento para o bem social" (POTTER, 2016, p. 197). Para concretizar o bem social, com suas variadas vias, interações e entrelaçamentos se necessita refletir com sabedoria e profundidade sobre um conjunto comum de valores humanos, em que haja respeito, liberdade e oportunidades para com todos os povos. O povo haitiano, em sua grande maioria, no processo de adaptação à realidade brasileira está buscando ferramentas, ritos e expressões religiosas para se sentir integrado a uma comunidade, obter apoio espiritual ou até mesmo material. Essa população precisa ser acolhida, respeitada e valorizada em seu protagonismo próprio.

\section{Considerações finais}

É atual e importante refletir sobre o povo haitiano, sua migração para o Brasil e o contexto de vulnerabilidade envolvido no processo. O contexto antropológico exige muito cuidado e humildade, pois apesar de estes assuntos estarem constantemente nos noticiários nos últimos anos, há múltiplas e complexas facetas a serem consideradas: histórica, econômica, sociopolítica, geográfica, ambiental, entre outras.

A teoria do coping religioso/espiritual e dos conflitos espirituais apresentada pela Psicologia da Religião constitui-se como ferramenta útil no exercício do cuidado espiritual às pessoas em condições existenciais de vulnerabilidade, bem como, a perspectiva da Bioética de Proteção, no entendimento das pessoas vulneradas.

O estudo sugere que a integração das crenças e valores religiosos nas práticas de cuidado aos imigrantes haitianos poderá ajudá-los a lidar com a vulnerabilidade e a transformar a condição de vulnerados por meio do empoderamento pessoal e com os recursos espirituais de que dispõem.

A ampliação da amostra no estudo deste tema pode levantar indicações importantes, tanto para pensar em melhores políticas de atenção a esse grupo, quanto para o planejamento de ações que visem fortalecer, por meio de assistência espiritual, os recursos internos de imigrantes para enfrentar sua condição de vulnerados. A Teologia, a Bioética, a Psicologia da Religião e as demais áreas das Ciências Humanas são convidadas a contribuir com seus conhecimentos e práticas, na produção de outra realidade para esse grupo. O cuidado pastoral/espiritual pode ser uma instância que contribua 
na transformação das condições de vulnerabilidade dessa população que historicamente sofre e luta por uma sobrevivência digna.

\section{Referências}

ARÁN, M.; PEIXOTO JUNIOR, CA. Vulnerabilidade e Vida Nua: Bioética e Biopolítica na Atualidade. Revista Saúde Pública, 850 p. 2007.

CHIARELO, L. M. Las políticas públicas sobre migraciones y la sociedade civil em América Latina. New York: Scalabrini International Migration Network, p. 167-169, 2011.

CNBB Comissão Episcopal para o Serviço de Caridade, da Justiça e da Paz. Mobilidade Humana no Brasil. Coord. Editorial Valdeir dos Santos Goulart. Brasília: Edições CNBB, 2009.

CORTESÃO, M. J. Z. 'O Povo Brasileiro.’ Vídeo disponível em: https://www.youtube.com/

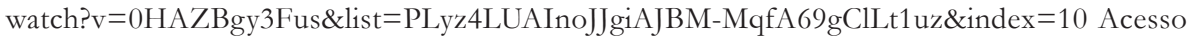
em: 22 mar. 2017.

CUMmingS J. P.; PARGAMENT K. I. (2010). Medicine for the Spirit: Religious Coping in Individuals with Medical Conditions. Religions, p. 28-53, 2010.

CUNHA, T.; GARRAFA, V. 'Vulnerability: A Key Principle for Global Bioethics?', Cambridge Quarterly of Healthcare Ethics, 25 (2), p. 197-208, 2016.

CUTTI, D. et al. Migração, trabalho e cidadania. São Paulo: EDUC, p. 59-87, 2015.

DESAI, K. M.; PARGAMENT, K. I. Predictors of growth and decline following spiritual struggles. International Journal for the Psychology of Religion, 25, p. 42-56, 2015.

DIEHL, F. O Fenômeno da Estigmatização dos Imigrantes Haitianos em Lajeado no Rio Grande do Sul. Barbarói, Santa Cruz do Sul, Edição Especial, n. 47, p., jan./jun. 2016, p. 90-106.

ESPERANDIO, M.; ESCUDERO, F.; FERNANDES, M.; PARGAMENT, K. (2018). Brazilian Validation of the Brief Scale for Spiritual/Religious Coping-SRCOPE-14. Religions, v. 9, p. 31.

EXLINE, J. J. Religious and spiritual struggles. In: K. I. Pargament (Ed.-in-Chief), J. J. Exline \& J. W. Jones (Associate Eds.), APA handbook of psychology, religion, and spirituality. Volume 1: Context, theory, and research (p. 459-475). Washington, DC: American Psychological Association, 2013.

EXLINE, J. J. et al. The Religious and Spiritual Struggles Scale: Development and initial validation. Psychology of Religion and Spirituality, v. 6 (3), p. 208-222, 2014.

FARIA, A. V. A Diáspora Haitiana para o Brasil: O Novo Fluxo Migratório (2010-2012). Dissertação de Mestrado PUCMG, 2012. Disponível em: http://www.biblioteca.pucminas. br/teses/TratInfEspacial_FariaAV_1.pdf. Acesso em: 21 fev. 2017.

FERNANDES, D.; MILESI, R.; FARIAS, A. Do Haiti para o Brasil: novo Fluxo Migratório. In: Refúgio, Migrações e Cidadania. Brasília: Instituto Migrações e Direitos Humanos, 2011. 
FOLKMAN, S. Personal control and stress and coping processes: A theoretical analysis. Journal of Personality and Social Psychology, 46, p. 839-852, 1984.

FOLKMAN, S.; LAZARUS, R.S. An analysis of coping in a middle-aged community sample. Journal of Health and Social Behavior, 21, p. 219-239, 1980.

FRIEDRICH, T. S. et al. Política Migratória e Universidade Brasileira: a experiência do atendimento a haitianos e outros migrantes na UFPR. Periplos. Revista de Investigación sobre Migraciones, v. 1, n. 1, 2017, p. 73-91.

GOTTARDI, A. P. P. De Porto a Porto: O Eldorado Brasileiro na Percepção dos Imigrantes Haitianos em Porto Velho - RO. Dissertação de Mestrado PUCRS. Disponível em: http:// repositorio.pucrs.br/dspace/bitstream/10923/7229/1/000468131-Texto\%2BCompleto-0.pdf. Acesso em: 20 mar. 2017.

Governo do ESTAdo DO PARANÁ Plano Estadual de Políticas Públicas para a Promoção e Proteção dos Direitos dos Refugiados, Migrantes e Apátridas do Paraná 2014-2016. Departamento de Direitos Humanos e Cidadania - DEDIHC, 2014.

HEFTI, R. The Extended Biopsychosocial Model: A whole-person-approach to psychosomatic medicine and psychiatry. Psyche \& Geloof, 24, p. 119-29, 2013.

HOSSNE, W. S. Dos referenciais da Bioética - a Vulnerabilidade. Revista Bioethikos. Centro universitário São Camilo. Disponível em: http://www.saocamilo-sp.br/pdf/ bioethikos/71/211-216.pdf. Acesso em: 15 mar. 2017.

INSTITUTO BRASILEIRO DE GEOGRAFIA E ESTATÍSTICA - IBGE. https://censo2010. ibge.gov.br/noticias-censo.html? busca $=1 \& \mathrm{id}=3$ \&idnoticia $=2018 \& \mathrm{t}=$ censo- 2010 -pais-temdeclinio-fecundidade-migracao-aumentos-escolarizacao-ocupacao-posse-bens $\& v i e w=$ noticia Acesso em 18 de março de 2017.

JERÔME, P. Depois da catástrofe, como estamos? In: Haiti por si - A reconquista da Independência Roubada. Org. Adriana Santiago. Fortaleza: Adital, 2013.

KOENIG H. G.; MCCULLOUGH M. E.; LARSON D. B. Handbook of religion and health (1 $1^{\text {st }}$ ed.). New York, NY: Oxford University Press, 2001.

LAZARUS, R. S.; FOLKMAN, S. Stress, Appraisal, and Coping. Springer: New York, NY, USA, 1984.

LOUIDOR, W. E. Uma História Paradoxal. In: Haiti por si - A reconquista da Independência Roubada. Org. Adriana Santiago. Fortaleza: Adital, 2013.

MAGALHÃES, L. F. A., BAENINGER, R. Trabalhadores Imigrantes: haitianos e haitianas em Santa Catarina - SC. In: Anais do VII Congreso de la Asociación Latino-Americana de Población e XX Encontro Nacional de Estudos Populacionais. Foz do Iguaçu-PR, 17 a 22 de outubro de 2016. Disponível em: http://187.45.187.130/ abeporgb/xxencontro/ files/paper/739-302.pdf. Acesso em: 23/03/2017.

MILESI, R. In: Os Novos Rostos da Imigração no Brasil: Haitianos no Rio Grande do Sul. Porto Alegre: CIBAI Migrações, 2014. 
MILESI, R.; ANDRADE, W. C. Atores e ações por uma lei de refugiados no Brasil. In: Barreto, L. P. T. F. (org.). Refúgio no Brasil - a proteção brasileira aos refugiados e seu impacto nas Américas. Brasília: ACNUR/CONARE-MJ, 2010.

PARGAMENT, K. I. (1997). Psychology of religion and coping. Theory, Research, Practice. New York: Guilford Press.

PARGAMENT, K. I. et al. Patterns of Positive and Negative Religious Coping with Major Life Stressors. Journal for the Scientific Study of Religion, 37 (4), p. 710-724, 1998.

PARGAMENT K. I.; FEUILLE M.; BURDZY D. The Brief RCOPE: Current psychometric status of a short measure of religious coping. Religions, 2: p. 51-76, 2011.

PARGAMENT, K. I.; KOENIG, H. G.; PEREZ, L. M. The many methods of religious coping: Development and initial validation of the RCOPE. Journal of Clinical Psychology, 56 (4), p. 519-543, 2000.

PATARRA, N. L. Migrações internacionais de e para o Brasil contemporâneo: volumes, fluxos, significados e políticas. São Paulo Perspec., São Paulo, v. 19, n. 3, p. 23-33, set. 2005.

POTTER, V. R. Bioética Ponte para o Futuro. São Paulo: Edições Loyola, 2016.

RISSON, A. P.; LIMA, A. C. C.; MATSUE, R. Y. Imigrantes Haitianos em Chapecó (SC): Acesso e Atenção à Saúde na Atenção Primária. In: Anais do I Congresso Internacional de Políticas Públicas de Saúde: Em Defesa do sistema Universal de Saúde (I Cipps). Chapecó: UFFS, 2017, v. 1, p. 1-2. Disponível em: https://periodicos.uffs.edu.br/index.php/CIPPS/ article/view/6967 Acesso em 26 de junho de 2018.

RODRIGUES, R.; DIAS, S. D. Encontro com a diferença: a perspectiva dos profissionais de saúde no contexto da prestação de cuidados aos imigrantes. Fórum Sociológico, v. 20, p. 1-13, 2012. https://journals.openedition.org/sociologico/583 Acesso em: 23/03/2017.

SCHRAMM, F. R. A moralidade da biotecnociência: a bioética da proteção pode dar conta do impacto real e potencial das biotecnologias sobre a vida e/ou a qualidade de vida das pessoas humanas? In: SCHRAMM, F. R.; REGO, S.; BRAZ, M.; PALÁCIOS, M. Bioética, riscos e proteção, 2. ed. Rio de Janeiro: UFRJ; Fiocruz, 2009. Cap. 1, p. 15-28.

SCHRAMM, F. R. Bioética da Proteção: ferramenta válida para enfrentar problemas morais na era da globalização. Revista Bioética, Brasília, v. 16, n. 1, p. 11-23, fev. 2008. Disponível em: <goo.gl/jLR3mx> Acesso em: 9 nov. 2016.

SILVA, J. C. L. Principais Correntes Migratórias para o Brasil. Brasil Escola. Disponível em: http://brasilescola.uol.com.br/brasil/principais-correntes-migratorias-para-brasil.htm Acesso em: 15 fev. 2017.

SILVA, L. M. M.; LIMA, S. S. Os imigrantes no Brasil, sua vulnerabilidade e o princípio da igualdade. Revista Brasileira de Políticas Públicas, v. 7, p. 385-403, 2017.

SILVA, S. A. Imigração e redes de acolhimento: o caso dos haitianos no Brasil. R. bras. Est. Pop., Belo Horizonte, v. 34, n. 1, p. 99-117, jan./abr. 2017.

STAUNER, N.; EXLINE, J. J.; PARGAMENT, K. I. (2016). Religious and Spiritual Struggles as Concerns for Health and Well-Being. Horizonte, Belo Horizonte, v. 14, n. 41, p. 48-75, jan./mar. 
UEBEL, R. R. G. Análise do Perfil Socioespacial das Migrações Internacionais para o Rio Grande do Sul no Início do Século XXI: Redes, Autores e Cenários da Imigração Haitiana e Senegalesa. Dissertação de Mestrado UFRS. Disponível em: http://www.academia. edu/12591420/An\%C3\%A1lise_do_Perfil_Socioespacial_das_Migra\%C3\%A7\%C3\%B5es_ Internacionais_para_o_Rio_Grande_do_Sul_no_In $\%$ C3\%ADcio_do_S\%C3\%A9culo_XXI_ Redes_Atores_e_Cen\%C3\%A1rios_da_Imigra\%C3\%A7\%C3\%A3o_Haitiana_e_Senegalesa Acesso em: 10 fev. 2017.

UEBEL, R. R. G. A mudança da Política Externa Brasileira para Imigrantes e Refugiados: O Caso da Imigração Haitiana no Início do Século XXI. Barbarói, Santa Cruz do Sul, Edição Especial n. 47, p. 22-43, jan./jun. 2016.

XAVIER, F. C. C. (2012). Migrações Internacionais na Amazônia Brasileira: Impactos na Política Migratória e na Política Externa. Tese de Doutorado Interinstitucional UFRR/ UnB/FLACSO. Disponível em: http://repositorio.unb.br/bitstream/10482/10739/1/2012_ Fernando\%20Cesar\%20Costa\%20Xavier.pdf Acesso em: 20 mar. 2017.

Submetido em: 16-4-2017

Aceito em: 10-8-2018 